\title{
Analisis e implicaciones de la Reforma al artículo 18 constitucional en materia de Derechos Humanos
}

\author{
Anabel Jiménez Murillo* \\ Recibido: 14 de febrero \\ Dictaminado: 17 de marzo
}

\section{Resumen}

El artículo 18 constitucional ha sufrido varias reformas a través del tiempo; la más significativa, por su incidencia actual, es la que tuvo lugar el 10 de junio de 2011. Su importancia tiene relevancia por su base en los Derechos Humanos: es en torno a éstos que el Sistema Penitenciario debe organizarse. Para ello es necesario implementar nuevos programas, dirigidos tanto a las personas privadas de la libertad, como a funcionarios que laboran dentro de este sistema. A casi cinco años de su realización, son muchos los puntos neurálgicos que deben ser examinados y, de manera armoniosa, modificarse para alcanzar los fines de la reforma.

Palabras clave: Reforma, sistema penitenciario, derechos humanos, indígenas, población carcelaria.

\section{Analysis and implications of the Reform to article 18 constitutional in Human Rights}

\begin{abstract}
The 18 article of the Constitution has undergone several reforms over time; the most significant for its current situation, was made on June 10, 2011. Its importance has its relevance based on Human Rights: it is around them that the prison system should be organized. This requires implementing new programs, aimed at both persons deprived of their liberty, as officials who work in this system. After nearly five years of its publication, many key points should be examined and harmoniously modified to achieve the aims of the reform.
\end{abstract}

* Docente Investigadora del Instituto de las Americas de Nayarit anahe.20@hotmail.com 
Key words: Reform, Prison system, Human Rights, Indigenous, prison population.

$$
\begin{array}{r}
\text { "La prisión es el único lugar en el que } \\
\text { el poder puede manifestarse de forma } \\
\text { desnuda, en sus dimensiones más } \\
\text { excesivas, y justificarse como poder } \\
\text { moral." }
\end{array}
$$

Michel Foucault

\section{Sumario}

I. Introducción; II. Recuento Histórico de las Reformas del artículo 18 Constitucional; III. reforma del 10 de junio de 2011; IV. El Régimen Penitenciario; V. La situación actual del sistema penitenciario; VI. Conclusiones; Bibliografía.

\section{Introducción}

Es bien sabido que una de las características del derecho es su constante transformación, de ahí que el primer mandamiento del Decálogo del Abogado de Eduardo Juan Couture sea: "Estudia. El Derecho se transforma constantemente...", sin embargo también es conocido que la mayoría de las legislaciones son resultado de un proceso lento, una consecuencia de la realidad que engloba situaciones o derechos que deberían ser positivizados desde mucho tiempo atrás; el caso que nos interesa es el reconocimiento de derechos humanos, mismos que a pesar de tener sus principios en la edad media (Cartas pueblas y fueros, emitidos por los reyes cristianos y señores laicos en la edad media, que dotaban de privilegios a ciertos grupos de la población), fueron reconocidos como tales y cobraron importancia varios siglos después en la Declaración Universal de Derechos Humanos, proclamada el 10 de diciembre de 1948.

No resulta extraño entonces que nuestro país, después de 63 años de la firma de la Declaración, reconozca los Derechos Humanos con un atraso de varias décadas en nuestra carta magna. Sin embargo, dicho "reconocimiento", tal y como la palabra lo indica, les da una existencia previa a dichos derechos, por lo 
tanto, nuestra constitución, transforma su calidad iuspositivista a iusnaturalista.

La finalidad de éste documento, es realizar un análisis del Artículo 18 de la Constitución Política de los Estados Unidos Mexicanos, a la que a partir de éste momento se le hará referencia mediante sus siglas, CPEUM, para acotamientos. Inicialmente, dicho artículo sin reformas, contaba solo con dos párrafos, a la fecha de hoy, posee nueve, derivación de los cambios que éste ha tenido a 98 años desde su publicación, siendo modificado y adicionado un total de siete veces.

Por lo que se puede observar, y a diferencia de otros artículos, han sido pocas pero muy representativas las modificaciones que éste ha sufrido, siendo imprescindible estudiar una de las más recientes e importantes, la reforma del 10 de junio de 2011. Hace referencia a la organización del sistema penitenciario, así como también a algunas prerrogativas que deben tener las personas privadas de la libertad para fomentar su reinserción social.

En ese entendido y con esos cambios - no sólo al artículo 18- se establecen los nuevos cimientos en el campo penitenciario que enfocan un punto importante: la protección de los derechos humanos. Por lo que las implicaciones que dicha modificación debe tener dentro del sistema penitenciario, en la praxis y en la sociedad, son de gran trascendencia para los juristas y la ciudadanía en general.

\section{Recuento histórico de las reformas del artículo 18 constitucional}

Precedentemente, nuestra Constitución de 1917 en su Artículo 18, contenido dentro del Título primero De las Garantías Individuales rezaba así:

"Sólo por delito que merezca pena corporal habrá lugar a prisión preventiva. El lugar de ésta será distinto y estará completamente separado del que se destinare para la extinción de las penas. Los Gobiernos de la Federación y de los Estados organizarán, en sus respectivos territorios, el sistema penal -colonias penitenciarias o presidiossobre la base del trabajo como medio de regeneración." 
En ésta primera versión, se distingue entre el lugar destinado a la prisión preventiva y aquél en donde se lleva a cabo la extinción o ejecución de la pena; se habla de las instituciones conocidas como penitenciarías y como deben estar organizadas.

Comenzaremos con un recuento de las reformas:

Primera reforma, publicada mediante Decreto el 23 de febrero de 1965 en el Diario Oficial donde se reforma y adiciona: Se modifican los párrafos primero y segundo, añadiendo, además, un tercero y cuarto. Se añade la capacitación para el trabajo y la readaptación social, toda vez que, consumada la pena, los presos pueden salir e integrarse al mundo laboral y social con los conocimientos adquiridos durante la compurgación de su pena. Se habla también, de una separación entre hombres y mujeres, dotándole a cada género de su espacio propio dentro de la prisión. Contempla también la educación, tema trascendente ya que busca la regeneración, que ya se contemplaba en el artículo sin la reforma.

Segunda reforma, publicada mediante Decreto el 4 de febrero de 1977, en el Diario Oficial de la Federación: Se adiciona un quinto párrafo al artículo 18 constitucional, proponiendo que todos aquellos reos mexicanos que se encuentren compurgando penas en países extranjeros puedan ser trasladados, si así lo desean, al territorio nacional para que cumplan sus condenas con base en los sistemas de Readaptación social; así mismo, aquellos reos con nacionalidad extranjera, que hayan sido sentenciados por delitos, puedan ser trasladados a su país de origen, observando los Tratados que haya celebrado México con ése efecto.

Tercera reforma, publicada mediante Decreto el 14 de agosto de 2001, en el Diario Oficial de la Federación: Se pronuncia un Decreto donde se reforman los artículos 1, 2, 4, 18 y 115 de la CPEUM. Dicho decreto adiciona un sexto párrafo al Artículo 18, que establece que el reo puede extinguir su pena en alguna penitenciaría cercana a su domicilio, para que, al finalizar, exista una mejor posibilidad para readaptarse o reintegrarse a una sociedad ya conocida.

Cuarta reforma, publicada mediante Decreto el 12 de diciembre de 2005, en el Diario Oficial de la Federación: Se reforma el párrafo cuarto; los párrafos quinto y sexto, ya conocidos, se cambian a séptimo y octavo, y en su lugar, se agregan nuevos párrafos quinto y sexto. Dedicando especial interés en el 1 tema de justicia para adolescentes. El párrafo cuarto, solo estipulaba que la Federación 
y Estados estaban obligados a establecer instituciones para adolescentes que incurrieran en la comisión de delitos con pena privativa de libertad; luego de la reforma se obliga también al Distrito Federal (Ahora Ciudad de México) que tiene una figura diferente a las de los Estados, quien en conjunto con la Federación y los Estados de acuerdo a la jurisdicción que les corresponda, debe establecer un sistema de justicia para adolescentes (Aquellos que se encuentren entre los doce y dieciocho años de edad) a quienes se les reconocerán sus derechos fundamentales.

Quinta reforma, publicada mediante Decreto el 18 de junio de 2008, en el Diario Oficial de la Federación: Donde se reforman los párrafos primero, segundo, tercero, séptimo y octavo, y se agrega un noveno párrafo. En el párrafo primero cambia de "delito que merezca pena corporal" a "delito que merezca pena privativa de libertad", como condición para la prisión preventiva; centrándose en aquellos delitos que impliquen la compurgación de la pena al interior de la prisión. El párrafo segundo que establecía que tanto la Federación como las Entidades Federativas eran las encargadas de tutelar las penitenciarías, ahora nos habla de un sistema penitenciario que se organizará sobre las bases del trabajo, la educación, la salud y el deporte, como medio para lograr la reinserción del sentenciado a la sociedad, procurando que no vuelva a delinquir.

Sexta reforma, publicada mediante Decreto el 10 de junio de 2011, en el Diario Oficial de la Federación. - Esta reforma modifica el párrafo segundo, que se estudiará en un apartado especial.

Séptima reforma, publicada mediante Decreto el 2 de julio de 2015, en el Diario Oficial de la Federación: Reforma el párrafo cuarto y el sexto del mismo artículo. En el primer párrafo modificado, se propone que el sistema integral judicial de justicia para adolescentes garantice los derechos humanos; en el segundo, se establece que el proceso en materia de justicia para adolescentes será acusatorio y oral.

\section{Reforma del 10 de junio de 2011}

Es el resultado de un proceso jurídico lento que ha ido gestándose con el paso del 
tiempo, dentro de niveles no solo nacionales sino también internacionales; sin embargo, un parte aguas significativo han sido los tratados que se han ratificado por nuestro país en materia de derechos humanos, estableciendo con ello, una necesidad imperante de instaurarlos dentro de nuestro sistema jurídico.

El jurista Antonio E. Pérez Luño, define a los derechos humanos como el conjunto de facultades e instituciones que en cada momento histórico concretan las exigencias de la dignidad, la libertad y la igualdad humanas, las cuales deben ser reconocidas positivamente por los ordenamientos jurídicos (Bidart, 1992). Definición que tiene nacimiento en el fundamento histórico-filosófico de dichas prerrogativas, que propone que dichos derechos, son producto de la historia atribuyéndoles una importancia que ha dejado huella con el paso del tiempo.

Los derechos humanos, se han ido desarrollando dentro del campo internacional; México, que forma parte activa dentro de dicha comunidad, ha firmado numerosos tratados en la materia, como lo son: la Carta de las Naciones Unidas, La Convención Americana sobre Derechos Humanos o el Pacto de San José de Costa Rica, entre muchos otros; versan sobre cuestiones de carácter general, aportando conceptos y características de los derechos humanos y las razones de su naturaleza inherente a cada ser humano o persona física por su cualidad humana. Existen otros tratados, no menos trascendentes, que se enfocan a puntos específicos, como la Convención contra la Tortura y otros tratos o penas crueles, inhumanos o degradantes, adoptada por la Asamblea General de las Naciones Unidas, y de la que nuestro país forma parte, el día 10 del mes de diciembre del año de 1984.

Por otro lado, nuestro país es uno de los Estados fundadores de la Organización de los Estados Americanos. Dicha organización fue creada el 30 de abril de 1948, con sede en el Distrito de Columbia en Estados Unidos de América y es un organismo de plena trascendencia en materia de derechos humanos, pues en la Carta de la Organización de los Estados Americanos, se establece la creación de la Comisión Interamericana de Derechos Humanos, un organismo trascendental que tendrá como función principal, la de promover la observancia y la defensa de los derechos humanos, servir como órgano consultivo de la Organización en esta materia.

La Corte Interamericana de Derechos Humanos, ubicada en San José, Costa 
Rica, tiene su nacimiento en la misma organización; debido al alcance de sus resoluciones en los Estados sobre los que tiene jurisdicción, es conocida por muchos, pues sus resoluciones han teniendo como consecuencia algunas de las reformas en materia de derechos humanos, instauradas en nuestra constitución política (recordemos que es el caso Radilla Pacheco Vs. Estados Unidos Mexicanos parte aguas de ésta reforma)

La trascendencia de éstas acciones es grande, tan es así que se ha establecido una jerarquía de los tratados internacionales que contengan normatividad relacionada al tema, misma que se encuentra prevista en el artículo 133 constitucional. Ha sido interpretada por la Suprema Corte de Justicia de la Nación, en la tesis 192,867; que les otorga una jerarquía superior a las leyes federales y en un segundo plano respecto de la constitución federal.

La reforma de 10 de junio comienza con la iniciativa con proyecto de decreto el día 21 de noviembre del año 2006, encaminada a reformar y adicionar los artículos $4^{\circ}$ y 73 de la Constitución Política de los Estados Unidos Mexicanos. Posteriormente, se fueron añadiendo otros artículos relevantes en materia de Derechos Humanos, los artículos 1, 3, 11, 15, 18, 29, 33, 89, 97, 102 y 105 fueron aprobados para su modificación o adición, por 310 votos a favor, 0 en contra y 3 abstenciones por la cámara de diputados, el día 23 de marzo de 2011. El decreto donde al mismo tiempo que los artículos anteriores, se modificó la denominación del Capítulo I del Título Primero, fue publicado en el Diario Oficial de la Federación el 10 de junio de 2011.

Se enmarcan el reconocimiento y la protección de los derechos humanos. Nuestro artículo 18 de la CPEUM de 1917, en su párrafo segundo, previamente rezaba:

"El sistema penitenciario se organizará sobre la base del trabajo, la capacitación para el mismo, la educación, la salud y el deporte como medios para lograr la reinserción del sentenciado a la sociedad y procurar que no vuelva a delinquir, observando los beneficios que para el prevé la ley. Las mujeres compurgarán sus penas en lugares separados destinados a los hombres para tal efecto" 
Se añade un elemento trascendental, ya que no es requisito previo contar con un título de licenciado en derecho, para notar los abusos que existen dentro del sistema penitenciario, que es el conjunto de disposiciones legales y de instituciones del estado que tienen por objeto la ejecución de sanciones penales de privación o restricción de la libertad individual (Contreras, 2003).

Por lo que, se modifica el artículo segundo para quedar de la siguiente forma:

"El sistema penitenciario se organizará sobre la base del respeto a los derechos humanos, del trabajo, la capacitación para el mismo, la educación, la salud y el deporte como medios para lograr la reinserción del sentenciado a la sociedad y procurar que no vuelva a delinquir, observando los beneficios que para el prevé la ley. Las mujeres compurgarán sus penas en lugares separados destinados a los hombres para tal efecto."

En la exposición de motivos, se consideró como un buen inicio, el reconocimiento de los derechos humanos en el sistema penal para evitar que las violaciones a éstos continuasen. En la mayoría de los casos, son incluso las mismas autoridades quienes se encargan de fomentar estas situaciones o victimizar a los reos. Se abordaron otros temas como el derecho a la educación, a un trabajo remunerado y a asistencia social, con la finalidad de que una vez que la persona privada de la libertad termine de compurgar su pena, pueda salir y se reintegre de manera eficaz a la sociedad.

No olvidemos que una de las características de los derechos humanos, es atribuida al iusnaturalismo que aduce a que éstos son inherentes a las personas físicas por el sólo hecho de su naturaleza humana; por lo tanto, existen a pesar de no estar estipulados en una norma dentro de un sistema jurídico. A raíz de la reforma, el Estado Mexicano, los está elevando a rango constitucional fomentando con ello, una observancia general, dentro de cualquier esfera jurisdiccional.

La reforma al párrafo segundo del Artículo 18, nace de igual manera de la modificación al artículo $1^{\circ}$ de misma fecha que dice:

“Todas las autoridades, en el ámbito de sus competencias, tienen la obligación 
de promover, respetar, proteger y garantizar los derechos humanos de conformidad con los principios de universalidad, interdependencia, indivisibilidad y progresividad."

Por lo tanto, es deber de la autoridad penitenciaria el velar y salvaguardar los derechos humanos, que son inherentes a la persona humana, esté o no privada de su libertad.

La prisión priva a los inculpados de su derecho al libre tránsito y otros derechos civiles y políticos: como el sufragio. Todos los demás le pertenecen dentro y fuera de una institución penitenciaria.

Recapitulando un poco, en el momento de establecer como base del sistema carcelario a los derechos humanos, se está dando la pauta para que todo un régimen, hasta ahora intocable, se modifique.

\section{EI Régimen Penitenciario}

En palabras de Contreras Nieto "El régimen penitenciario es la suma de condiciones que requiere una institución penitenciaria para alcanzar el logro de los fines que tiene cada sanción penal respecto a su destinatario" (Contreras, 2003, p.13). A raíz de la reforma, no sólo será necesario tener un personal que cuente con instrucción sobre derechos humanos, sino igualmente proporcionar las circunstancias necesarias para la observancia de los mismos; entre éstas la modificación de los sitios penitenciarios en aras de que no se vulneren los principios que han sido establecidos previamente en los tratados.

En correspondencia a lo expuesto es importante que señalemos, por su fuerza y preeminencia en el tema en comento, el instrumento conocido como Los Principios y Buenas Prácticas sobre la Protección de las Personas Privadas de la Libertad (publicado mediante la resolución 1/08, por la Comisión Interamericana de Derechos Humanos) vinculante para nuestro país, pues como ya se dijo anteriormente, forma parte activa de la Organización de los Estados Americanos, de la que depende dicha comisión. 
Los Principios y Buenas Prácticas sobre la Protección de las Personas Privadas de la Libertad son resultado de la crítica situación de violencia, hacinamiento y la falta de condiciones dignas de vida en distintos lugares dedicados a la privación de libertad en las Américas. En éste documento se establecen un conglomerado de principios generales para una buena observación de los derechos humanos. Entre aquellos imprescindibles para el funcionamiento de un buen sistema penitenciario se encuentran: El trato humano, la igualdad y no-discriminación, la libertad personal, el derecho a la salud, la alimentación y agua potable; albergue, los medios de higiene necesarios para el ser humano y vestido; trabajo apropiado, así como algunas medidas contra el hacinamiento; entre otros.

Uprimny y Guzmán señalan que los derechos de las personas en reclusión pueden ser clasificados en tres grupos: Suspendidos, que son aquellos que se suspenden por el solo hecho de estar en prisión; limitables, que pueden ser restringidos por necesidad, pero solo temporalmente y en caso de existir ciertas condiciones; e intangibles, que son los derechos que por su naturaleza no pueden ser restringidos a la persona privada de libertad (Pérez, 2011).

La reforma busca precisamente, proteger los derechos del reo que son intangibles, derechos humanos importantes para su salud o integridad física, que establecen las condiciones mínimas que deben observarse al interior de las prisiones. Derechos que son imposibles de respetar al interior de los penales que nuestro México tiene.

\section{La situación actual del Sistema Penitenciario}

A casi seis años de la reforma hay muchas cuestiones relevantes que deben observarse: sus alcances son muchos, pero sus impedimentos excesivos, ya que todavía falta mucho por hacer.

Las instituciones penitenciarias en nuestro país son focos de violaciones a los Derechos Humanos, desde el incontrolable hacinamiento mencionado de forma imprecisa anteriormente (Un análisis, documenta que existen 242 mil 754 internos en las cárceles mexicanas, en un espacio diseñado para un máximo de 
195 mil 278), hasta la prostitución de las mujeres para obtener dinero, debido a que no existen los medios mínimos de higiene y vestido, de alimentación y agua potable libertad (Pérez, 2011).

Ahondaremos entonces, en éstos requisitos mínimos y la situación actual de los mismos en nuestro país.

Según el Informe Sobre La Situación De Las Personas Privadas De La Libertad, en nuestro país se potencia el uso de la prisión preventiva por encima de cualquier otro medio de compurgación de penas. De los 389 centros penitenciarios, el 54\% de estos centros de reclusión tienen registros de sobrepoblación (Méndez, 2014). Las entidades federativas con mayores porcentajes en sobrepoblación carcelaria son Nayarit (128.74\%), el Estado de México (97.82), Hidalgo (87.52) y la Ciudad de México (81.13\%).

El hacinamiento, es el principal generador de violaciones a derechos humanos, toda vez que al no existir un espacio adecuado se violenta la dignidad de la persona humana (Sí, es la misma de la que Kant nos hablaba y que otorga preeminencia los seres humanos, el fin en sí mismos). La sobrepoblación penitenciaria es algo que podría evitarse, reduciendo el número de presos; empero las irregularidades en el acceso a la justicia y el debido proceso crean un muro infranqueable. De lo anterior, es plausible, tomar en cuenta una supresión de la sanción carcelaria en algunos delitos no graves, para propiciar el uso prudente de la prisión, ya que 42.9 por ciento de la población carcelaria, son personas que están por delitos de robo; el 17.3 se encuentran por homicidio (Pérez, 2011).

El problema de aglomeración puede ocasionar problemas de indisciplina por parte de los reos, generando un ambiente afable para la corrupción: la extorsión forma parte activa en el día a día de quienes se encuentran compurgando una pena en cualquier parte del país. Según el informe México Evalúa, más del 60 por ciento de la población en reclusión purga penas menores a tres años, por delitos no graves ni violentos, además de los miles de presos que, sin haber sido declarados culpables y sin ser un riesgo para la sociedad, son privados de su libertad (Solís y De Buen, 2013). Por lo que, haciendo caso a las cifras, estamos ante una población considerable que pudo haber evitado caer en el foso de las prisiones.

Un claro ejemplo de nuestro dicho es lo acontecido al interior del penal Topo 
Chico, donde las condiciones de ingobernabilidad permitieron enfrentamientos entre grupos rivales. La Organización de las Naciones Unidas, se pronunció a favor de la familia de las víctimas con el fin de que el Estado garantice la reparación del daño, exigiendo también a México una investigación imparcial para esclarecer los hechos; el relator de éste organismo había visitado ya algunas penitenciarias en el año 2014, donde se dio cuenta que existía una "flexibilidad excesiva", ya que el autogobierno y las situaciones de violencia, son fomentados por las mismas autoridades penitenciarias.

Dicha situación no es extraña dentro de este ambiente, pues las numerosas deficiencias, que no son ignoradas por los políticos, en el sistema penitenciario propician situaciones límite.

A menudo ocurren siniestros donde los delincuentes al frente, incitan a los demás a las riñas u homicidios. El caso del penal Topo Chico no es aislado, también en la prisión denominada El Amate, ubicada en Cintalapa en el Estado de Chiapas, ocurrieron agravios. Los hechos llegaron a conocimiento de la Comisión Nacional de Derechos Humanos (En adelante CNDH) que emitió una recomendación dirigida al gobernador Coello. Le informaba de las condiciones que guarda (aún persisten) el centro penitenciario en comento, debido a que la inseguridad y falta de vigilancia propiciaron el asesinato de un interno, que fue encontrado colgado sin vida.

Claramente estamos ante un problema con especial relevancia, que no debe ser ignorado y por eso no es extraño que muchos juristas se hayan preocupado por este punto neurálgico de nuestro sistema jurídico. En palabras del Dr. Sergio García, en el interior de los penales se puede observar claramente, un verdadero mercado de miseria humana, pues su organización se torna a favor de los reos que más tienen, quienes de la mano de los funcionarios que ahí laboran, realizan cobro de cuotas excesivas para protección de los demás compañeros carcelarios o para que estos puedan tener acceso a un cuarto. La desigualdad social no solo puede observarse en los límites de las grandes ciudades, también hace presencia en situaciones de cárcel, donde siempre aparece de forma inclemente: Mientras algunos tienen acceso a televisión por cable, otros viven en pequeños cuartos que tienen que compartir hasta con cuarenta personas.

La revisión de la infraestructura es, por lo tanto, otra cuestión de valor, 
pues es la que propicia a la inobservancia de los derechos fundamentales, no existe un número de penitenciarías proporcional a la población carcelaria. Se ha comentado hasta el cansancio que la inversión estatal e inclusive del campo privado, podría ser la solución para garantizar y rescatar también otros derechos: a la salud, la alimentación y una vivienda digna, de cada reo.

La reforma que hemos explicado, instaura que una de las bases del sistema penitenciario será la educación como medio para la reinserción y la no reincidencia. Esto implica un sinfín de situaciones, entre ellas, instaurar universidades dentro de las prisiones con el único motivo de que los presos, una vez liberados de la carga jurídica que implica compurgar sus penas, puedan incorporarse plenamente al mercado laboral.

El Estado también debe proporcionar educación a los servidores públicos que se desempeñan dentro de este campo laboral, por ello, la Universidad Nacional Autónoma de México presentó, de la mano del investigador Sergio García Ramírez, una propuesta para rescatar los derechos humanos en el sistema carcelario, que tiene como objetivo proporcionar educación a los servidores públicos que laboran dentro de éstos centros de privación de libertad, para que se sensibilicen con base en los derechos humanos.

Es de puntual trascendencia mencionar que año con año las quejas ante la $\mathrm{CNDH}$, referentes a los abusos que las personas en prisión sufren a cargo del personal técnico, van en aumento. Dichas quejas evidencian las agresiones verbales y físicas que sufren, entre ellas mencionan haber sido golpeados, quemados, mojados e inclusive, abusados sexualmente; otros menos agraviados han sufrido la aplicación de toques eléctricos y gas.

Consideramos que además de la educación que se pretende impartir, sustentada en los derechos humanos, debe establecerse un régimen de vigilancia para los funcionarios que laboran en estas instituciones, que son focos permanentes de abusos de autoridad. Evitando con eso que se crean por encima de la ley.

Es imperativo implementar la educación para personas privadas de libertad, que sigue rezagándose, tan es así que en la actualidad no hay progresos en este punto, $y$, aunque muchos celebren la existencia de un alumno que se graduó de la Licenciatura en Psicología, no podemos encomiar ésta situación, debido a que se trata de un caso especial: Dicho alumno fue aprehendido cuando estaba a punto 
de terminar sus estudios por lo que al estar en el centro penitenciario se dedicó a redactar su tesis. Es notable la falta de interés en proporcionar una profesión a aquellos que no la tienen, que no cuentan con los medios para acceder a ella. Debe establecerse una red de universidades al interior de las instituciones carcelarias, para fomentar su reinserción social, participación laboral y no reincidencia que tanto se busca con ésta reforma.

El término educación no solo involucra lo ya aludido: un enfoque académico que proporcione herramientas a los inculpados y una sensibilización para las personas que conviven con ellos diariamente, con motivo de su empleo; sino también sensibilizar a la sociedad y al propio Estado, pues uno de los requisitos básicos para trabajar en cualquier esfera sea institucional o privada, es la conocida "carta de antecedentes no penales" que otorga una situación de desigualdad; de nada sirve que el sistema penitenciario tenga como base la educación y el trabajo, si al extinguir sus penas y tratar de obtener un empleo, las personas serán vistas con malos ojos, pues es sabido de antemano que la discriminación laboral en este ámbito se produce ampliamente.

La discriminación no sólo existe en la sociedad que se encuentra al exterior. Los grupos vulnerables, como indígenas, mujeres y personas con discapacidades mentales que también han sido sancionados con la pena privativa de libertad presentan índices altos en segregación al interior de las cárceles donde no existen las condiciones mínimas que un ser humano requiere para su subsistencia (como las ya citadas). Estos derechos imprescindibles para una persona, pasan a ser parte de aquellos privilegios a los que sólo unos cuantos pueden tener acceso.

De acuerdo al censo presentado por la Comisión Nacional para el Desarrollo de los Pueblos Indígenas, existen más de 8 mil presos indígenas en nuestro país, de los cuales, el $96 \%$ son hombres, quienes se encuentran privados de la libertad, en la mayoría de los casos por delitos del fuero común. El mismo organismo ha conseguido la excarcelación de más de 2,500 indígenas entre el 2013 y 2014, con el apoyo de 576 interpretes-traductores. Sin embargo, se trata de una cifra muy pequeña en concordancia con el total de personas indígenas que se encuentran encarceladas. A la fecha, estas son las cifras más actualizadas.

La población indígena, es el grupo más vulnerable ya que debido a su situación económica, no puede tener acceso a una defensa adecuada. Aunado a 
la falta de conocimiento del idioma español, propicia el ambiente perfecto para que los funcionarios públicos los obliguen a firmar confesiones que los confirmen como culpables, sin que éstos tengan una idea de lo que están ratificando.

La promoción y el cuidado de la salud, siendo éste uno de los objetivos del nuevo sistema penitenciario mexicano, es otro tema que no debe olvidarse. No hay un acceso eficiente a los servicios de salud; en el caso de los medicamentos, son los familiares de los reclusos y éstos últimos quienes deben conseguirlos.

A partir del 2014 en adelante, la CNDH ha recibido quejas de internos sobre la falta de medicamentos al interior de las instituciones penitenciarias. Dicha Comisión emitió una recomendación para que se brinde atención médica integral y se proporcionen medicamentos para que se atiendan padecimientos de todos los quejosos.

Los abusos sexuales imperan como situaciones cotidianas debido a la insumisión, sin embargo, no solo acontecen entre los mismos reos (A menudo se sabe que este tipo de escenarios suceden entre los mismos compañeros carcelarios) sino también son fomentadas y a veces, ejecutadas por el personal técnico que labora en dichas instituciones.

Por otro lado, la contaminación criminógena, sin importar etnia o condición social, a que son sujetos las personas privadas de la libertad, debido a su convivencia diaria con verdaderos criminales, hace muy difícil la tan anhelada reinserción social.

El nuevo sistema de justicia penal, en la justicia alternativa, busca la solución por otras vías: algunos delitos no graves pueden ser compurgados de forma distinta por medio de sanciones ya sea pecuniarias o de trabajo social. Todo ello, como medio para evitar precisamente dicha contaminación. Se exceptúan los supuestos en donde opere la delincuencia organizada, la trata de personas, homicidio doloso, violación y secuestro.

Se pueden contemplar como algunas sanciones alternativas a la pena de prisión: El trabajo en favor de la comunidad (cuando la pena no exceda de cinco años) que se realizará en instituciones educativas o de asistencia, de forma gratuita, sin que interfiera en la subsistencia del reo; El tratamiento en libertad donde el sentenciado podrá realizar algunas labores bajo la supervisión de la autoridad ejecutora; y la semilibertad, que es la alternación de periodos 
cortos de reclusión y libertad. Estas instituciones consideran la investigadora, fomentarán la reinserción social evitando también el hacinamiento y los gastos que éste conlleva, la inobservancia de los derechos humanos y la contaminación criminógena (Fernández, 1994).

En la Ley Federal de Ejecuciones de Sanciones Penales, publicada con motivo de la reforma de 2008 en materia de juicios orales y con fundamento también en la reforma que aquí se estudia, se establece en el título tercero, algunas sanciones no privativas de libertad como lo son: La sanción pecuniaria, consistente en una multa establecida por la autoridad ejecutora; El tratamiento en libertad, a cargo de la autoridad penitenciaria para propiciar la readaptación social; La semilibertad, consiste en la externación durante la semana de trabajo o educativa y reclusión durante el resto de la semana o diurna; y El trabajo a favor

de la comunidad donde la Secretaría del Interior es responsable de la ejecución de un trabajo establecido por la autoridad ejecutora, en jornadas de un máximo de cuatro horas diarias y en períodos distintos al horario de labores.

Uno de los fines del nuevo sistema penal acusatorio es precisamente evitar las situaciones que hemos estudiado y hecho hincapié continuamente; lo interesante será observar ya en la praxis, ese panorama esperanzador, así como sus consecuencias en el campo del derecho penal y nuestra sociedad.

\section{Conclusiones}

En la edad media, las primeras sanciones consistían en ejecuciones públicas, conocidas como espectáculo punitivo o el suplicio, que además de dañar físicamente el cuerpo del culpable, era visto como medio de represión para que la población observara lo que podía suceder si no obedecía a la ley (Foucault, 2003). La mayoría de aquellos que perecieron por estas medidas, lo hicieron sin un juicio justo, pues desde entonces se trataba a los criminales como una persona sin derechos que quedaba a merced del rey. Con el tiempo, las penas fueron cambiando hasta llegar a la creación de la primera cárcel, con reglas, custodios, panópticos y trabajo. En nuestros días la privación de la libertad como método 
de desahogo de las penas es la más utilizada, el castigo universal que se realiza en todos los países.

En el caso actual, todavía se ignoran los derechos de las personas recluidas, lo que implanta las bases de la reforma que comentamos que, aunque sea pequeña presenta varios retos para el sistema penitenciario; considerando que sus alcances abarcan temas de relevancia internacional, es obligación de nuestro país de realizar las acciones tendientes a la observación de dicho artículo. Cambios que no serán nada fáciles, ya que se necesita una nueva formación y sensibilización por parte de los operadores judiciales y administrativos, pues existen cursos para la sensibilización tanto para el personal de los centros penitenciarios como para abogados, todo esto con motivo de los derechos humanos, para todo aquel que labore en instituciones de tipo púnico, pues muchas veces son los primeros en fomentar las violaciones a derechos humanos, ya que utilizan a menudo la Ley del Talión como método para calificar a los presos, siendo tratados con desprecio por las acciones que éstos hayan realizado.

Es imprescindible que, en aras de fomentar la observación de los derechos humanos, se realicen constantes escrutinios a todos y cada uno de los lugares con fines penitenciarios para que se vigile ese correcto funcionamiento. Por otro lado, la utilización de las alternativas observadas es indiscutible, pues es una de las formas de extinguir el hacinamiento. La implementación de mayor número de cárceles para mujeres, evitará los constantes abusos sexuales que son el día a día en estos recintos.

Sin duda alguna, las intenciones de los legisladores parecen buenas, pero de nada sirve, lo que se ha venido señalando: la creación de reformas si éstas no se ponen en práctica, que es un problema muy común en nuestro derecho. Como sabemos, nunca hay suficiente elemento económico para éste tipo de instituciones, siendo precisamente éste el motivo de la situación actual que guardan todos los sitios penitenciarios.

A pesar del tiempo transcurrido, aún podemos ver un horizonte oscuro en cuanto a la aplicación de la misma, pues tangiblemente han sido muy pocos, por no decir ínfimos. Hacemos especial hincapié en que urge un sistema de control que analice si los derechos humanos están siendo observados al interior de las penitenciarías, ya que son muchas las quejas que la Corte Interamericana de 
Derechos Humanos ha recibido por parte de las personas que se encuentran en éstos supuestos.

Es un paso trascendental que, a la larga, se espera que implique nuevas consecuencias a la sociedad, pues cualquiera que haya estado en prisión, podrá participar como un ciudadano que genere con su trabajo, activos para que nuestro país pueda salir adelante. Además, los cambios sociales que se podrán dilucidar, de ser observable en todos sus puntos esta reforma, traerán como resultado una sociedad más justa, que apoye a sus integrantes y evite estigmatizar a quienes por alguna u otra razón, hayan tenido que permanecer reclusos para como cualquier ciudadano, responder por la no observancia de las normas.

\section{Bibliografía}

Asilegal. (2013). Informe EPU sobre Sistema Penitenciario en México. Recuperado de: http://132.247.1.49/webEPU/images/stories/ OSC/6_AsiloLegal.pdf. Fecha de consulta: 14/12/2016.

Bidart, G. (1992). Teoría general de los derechos humanos. México: Universidad Nacional Autónoma de México, Instituto de Investigaciones jurídicas.

Carta de la Organización de los Estados Americanos (1949), Serie sobre Tratados, Número 1609, 1949, 13, enero.

Coatecatl, J. (14 de febrero 2016). Sistema carcelario, mercado de miseria. La Razón. Recuperado de http://razon.com.mx/spip. php?article205663. Fecha de consulta: 08/01/2016.

Contreras, M. (2003)10 temas de derechos humanos. México: Artículos impresos.

Decreto por el que se modifica la denominación del Capítulo I del Título Primero y reforma diversos artículos de la Constitución Política de los Estados Unidos Mexicanos (2011, junio). Diario Oficial de la Federación. recuperado de: http://www.diputados.gob.mx/ LeyesBiblio/proceso/1xi/117_DOF_10jun11.pdf. Fecha de consulta: 
05/02/2017.

Fernández, D. (1994). Sanciones alternativas a la pena de prisión. Propuesta de Reformas a la Legislación Penal Mexicana. Boletín Mexicano de Derecho Comparado, México. Núm. 81.

Foucault, M. Vigilar y Castigar, nacimiento de la prisión. México: Siglo XXI.

La redacción (30 de marzo de 2016) Carecen reos de medicinas". Zócalo Saltillo recuperado de: http://www.zocalo.com.mx/seccion/ articulo/carecen-reos-de-medicinas-1459347262. Fecha de consulta: $14 / 12 / 2016$.

La redacción (22 de marzo de 2016)CNDH emite recomendación a Velasco Coello por deficiencias en penal amate. Proceso. Recuperado de: http://www.proceso.com.mx/434383/cndh-emite-recomendaciona-velasco-coello-deficiencias-en-penal-amate. Fecha de consulta: $14 / 12 / 2016$.

La redacción ( 3 de abril de 2016) CNDH: Presos del penal federal de Tepic sin atención médica ni medicinas suficiente, Nayarit en línea. Recuperado de: http://www.nayaritenlinea.mx/2016/04/03/ cndh-presos-del-penal-federal-de-tepic-sin-atencion-medica-nimedicinas-suficientes?vid=86422. Fecha de consulta: 15/12/2016.

Méndez, J. (2014, abril). Informe sobre la situación de las personas privadas de la Libertad, Visita a México del Relator Especial de Naciones Unidas sobre la tortura y otros tratos crueles, inhumanos o degradantes. México.

Pérez, C. (2011) De la Constitución a la Prisión. Derechos Fundamentales y Sistema Penitenciario. La Reforma Constitucional en Derechos Humanos: Un nuevo paradigma, México: UNAM, Instituto de Investigaciones Jurídicas.

Principios y Buenas Practicas sobre la Protección de las Personas Privadas de la Libertad en las Américas (Resolución 1/08) (2008).

Solís, L., y De Buen, N., (2013). La cárcel en México ¿Para qué?, México Evalúa. Centro de Análisis de políticas públicas, México, pp. 5. 
